\title{
RECONSTRUÇÃO PALEOAMBIENTAL DO MACIÇO DE ÁGUA BRANCA, SEMIÁRIDO DE ALAGOAS, A PARTIR DA ANÁLISE DOS SEDIMENTOS DE ENCOSTA
}

\author{
Maria Luísa Gomes da Silva ${ }^{1}$ \\ Flávia Jorge de Lima² \\ Antônio Carlos de Barros Corrêa ${ }^{3}$
}

Resumo: A pesquisa teve como objetivo analisar depósitos sedimentares localizados no maciço de Água Branca - AL, região Nordeste do Brasil, abordando os mesmos como evidências de mudanças na dinâmica paleoambiental ao longo do Holoceno. Para tanto, realizou-se a análise granulométrica e morfoscópica dos sedimentos, além da datação absoluta dos grãos de quartzo pelo método da LOE. Os resultados mostraram sedimentos relativos a três fases deposicionais. O colúvio mais antigo data de $10200 \pm 880$ anos AP e apresenta características sedimentares de cascata. O depósito do Holoceno Médio possui idade de $4590 \pm 325$ anos, mostra que, com a diminuição da umidade os depósitos estão associados aos eventos torrenciais. Por fim, os três depósitos referentes ao Holoceno Superior compreendem o período entre 3900 e 3100 anos AP e mostram predominância de um clima semiárido, com pontuais precipitações torrenciais. Os colúvios apresentaram características sedimentológicas semelhantes, sendo compostos em sua maioria por fluxos de lama, com exceção apenas de uma camada do perfil Preguiçoso, que foi formada pelo processo de fluxo de detrito

Palavras-chave: Mudanças paleoclimáticas. Holoceno. Semiárido do Nordeste do Brasil.

\section{PALEOENVIRONMENTAL RECONSTRUCTION OF THE ÁGUA BRANCA MASSIF, ALAGOAS STATE SEMI-ARID, BASED ON THE ANALYSIS OF HILLSLOPE SEDIMENTS}

Abstract: The research aimed to analyze sedimentary deposits located in the Água Branca massif, State of Alagoas, northeast of Brazil, approaching them as evidence of changes in paleoenviromental dynamics along the Holocene. Therefore, granulometric and morphoscopic analysis of the sediments were carried out, alongside with the absolute dating of the quartz grains by the OSL method. The results showed that sediments stored in landscape relate to three depositional phases. The oldest colluvium dates from $10200 \pm 880$ years BP and demonstrate sedimentary characteristics of cascade. The Middle Holocene deposit is $4590 \pm 325$ years old, indicate that, with the decrease in humidity the deposits are associated with torrential events. Lastly, the three deposits referring to the Late Holocene cover the period between 3900 and 3100 years BP and prove the predominance of a semiarid climate, with punctual torrential rains. Colluvium deposits presented similar

\footnotetext{
${ }^{1}$ Universidade Federal de Pernambuco, Departamento de Ciências Geográficas, Recife, Brasil, mluisags19@gmail.com, https://orcid.org/0000-0002-5911-3988

2 Universidade Federal de Alagoas, Curso de Geografia, Delmiro Gouveia, Brasil, flavia.limageo@gmail.com, https://orcid.org/0000-0003-4176-5854

${ }^{3}$ Universidade Federal de Pernambuco, Departamento de Ciências Geográficas, Recife, Brasil, dbiase2001@terra.com.br, https://orcid.org/0000-0001-9578-7501
} 
sedimentological characteristics, they are composed mostly of mud flows, with the exception of just one layer of drebris flow at the Preguiçoso site.

Keywords: Paleoclimatic changes. Holocene. Semi-arid Northeast Brazil.

\section{RECONSTRUCCIÓN PALEOAMBIENTAL DEL MACIZO ÁGUA BRANCA, SEMIÁRIDO DE ALAGOAS, DESDE UN ANÁLISIS DE LOS SEDIMENTOS DE LADERA}

Resumen: La investigación tuvo como objetivo analizar los depósitos sedimentarios ubicados en el macizo Água Branca - AL, región noreste de Brasil, abordándolos como evidencia de cambios en la dinámica paleoambiental a lo largo del Holoceno. Para este propósito, se realizó un análisis físico, granulometría y morfología de sedimentos, así como la datación absoluta de granos de cuarzo por el método LOE. Los resultados mostraron que sedimentos relacionados con las tres fases deposicionales del Holoceno existen en el paisaje. El coluvión más antiguo data de $10200 \pm 880$ años AP y demuestra características sedimentares de cascada. El depósito del Holoceno Medio tiene $4590 \pm 325$ años, muestra que, con la disminuición de la humedad los depósitos están asociados com eventos torrenciales. Por fin, los tres depósitos que se refieren al Holoceno Tardío cubren el período entre 3900 y 3100 años AP. Los coluviones presentaron características sedimentológicas similares, estando compuesto principalmente de flujos de lodo, a la excepción de un estrato de fluxo de escombros en el perfil Preguiçoso.

Palabras clave: Cambios paleoclimáticos. Holoceno. Semiárido del Noreste de Brasil.

\section{Introdução}

As dinâmicas subaéreas são responsáveis pelo reafeiçoamento das diferentes formas do relevo, podendo ser divididas em modelados de acumulação, onde ocorre a agradação, e denudação, onde predomina a erosão. Em uma abordagem sistêmica Mabesoone (1983) expõe que os modelados de acumulação, como as encostas coluviais, resultariam da ação de um modelo processo-resposta, onde os processos seriam definidos pelo tipo de energia que opera o sistema, e este seria regulado pelas características fisiográficas da área. Deste modo, os sedimentos apresentariam as características dos elementos que possibilitaram a sua formação.

Assim, a maioria das encostas tem uma longa história de desenvolvimento, que pode fornecer informações sobre as taxas de mudanças, frequência de eventos geomórficos passados e paleoambientes. A evidência de eventos passados torna-se mais acessível à pesquisa geomorfológica em encostas com cobertura coluvial, e os dados paleoambientais podem estar associados a paleo-horizontes pedológicos inumados assim como às propriedades sedimentológicas e geocronológicas dos 
próprios depósitos. A interpretação desse material requer, entretanto, uma compreensão de suas posições numa paisagem antiga (SELBY, 1993).

No mundo tropical, não glaciado, as diversas oscilações climáticas ocorridas ao longo do Quaternário deixaram vestígios que ainda estão presentes no atual modelado. Contudo, os processos envolvidos e a temporalidade dos materiais demandam um estudo mais verticalizado das coberturas superficiais associadas, sobretudo, às formas de agradação (SALGADO LABOURIAU, 1994 e SUGUIO, 2010).

Os estudos de geomorfologia do Quaternário sobre a paisagem do Nordeste semiárido do Brasil vêm crescendo no transcurso das últimas décadas. A maior parte das pesquisas aponta para a deposição de sedimentos estruturadores da paisagem ao longo do Quaternário Tardio, com pulsos importantes de deposição durante o Último Máximo Glacial, transição Pleistoceno/Holoceno e Holoceno médio (Corrêa, 2001; Bezerra et al., 2008; Gurgel et al., 2013; Lira, 2014 e Mutzenberg et al., 2015). Esses autores demonstraram em bases empíricas que no Nordeste semiárido a paisagem geomorfológica armazena registros das mudanças ambientais do Quaternário, responsáveis pela elaboração do relevo, evidenciando a existência de pulsos climáticos úmidos alternados com fases áridas e semiáridas.

A área de estudo está localizada no extremo oeste semiárido do estado de Alagoas, sobre o maciço de Água Branca, no qual se encontra a maior parte do município homônimo (Figura 01). O maciço constitui um dos diversos plútons graníticos brasilianos que margeiam o Planalto da Borborema, a nordeste, e definem espaços subúmidos diferenciados em função da maior altitude. Os depósitos de encosta são em sua maioria delgados e poucos expressivos, costumam apresentar fenoclastos isolados imersos na matriz e também cascalheiras, que fornecem evidências de mudanças na intensidade dos processos de encosta ocorridos na área. 
Figura 01 - Mapa de localização dos pontos de coleta no maciço Água Branca - AL.

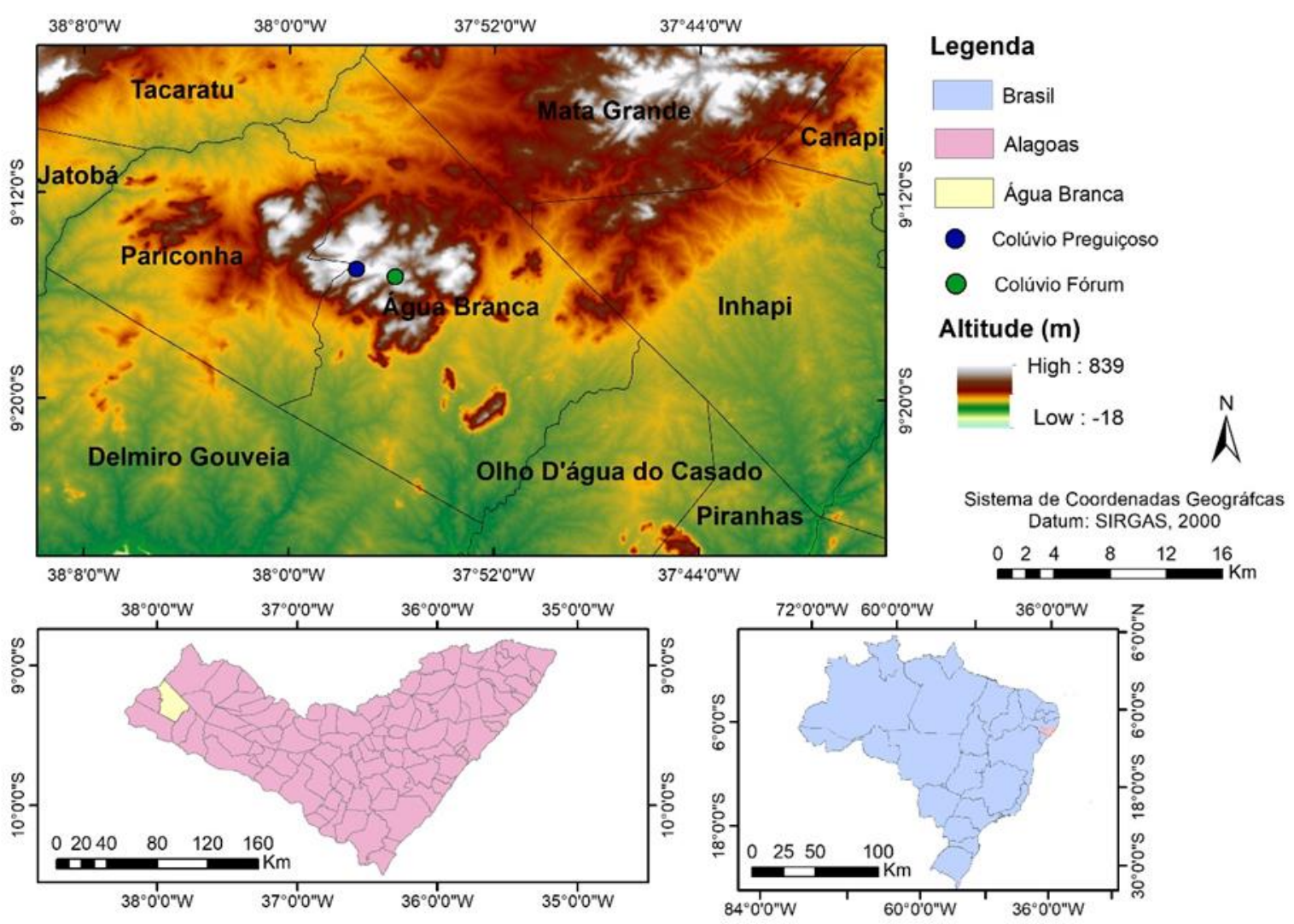

Fonte: Autores, 2020.

A pesquisa teve como objetivo analisar depósitos de encostas localizados no maciço de Água Branca e correlacioná-los com outros já estudados para o Nordeste semiárido com o intuito de compreender as condições paleoambientais associadas à sua gênese. Neste sentido, o trabalho procurou estabelecer relações entre os dados geocronológicos encontrados na região e aqueles disponíveis para a área de estudo.

\section{Caracterização da área de estudo}

O clima predominante na área é o tropical semiárido, cuja precipitação anual é marcada por um período chuvoso que se estende de maio a agosto, e por uma estação seca que abrange os demais meses com taxas variáveis de precipitação, sendo dezembro e janeiro particularmente secos. Devido à altitude, que chega a 800 m, a precipitação média anual do município de Água Branca é de 879mm (SEPLAG, 2018), bastante superior aos totais da depressão ao entorno.

Entre os sistemas atmosféricos que influenciam o regime de chuvas, destacam-se a Zona de Convergência Intertropical (ZCIT) durante o seu posicionamento ao sul do equador, as Frentes Frias (FF), os Vórtices Ciclônicos de Altos Níveis (VCAN), as linhas de Instabilidade (LI) e os Complexos Convectivos de 
Mesoescala (CCM), caracterizados por precipitações fortes e de curta duração. Dentre os sistemas de teleconexão climática responsáveis pelo aumento das precipitações na área destaca-se o Dipolo do Atlântico, que aumenta a intensidade e frequência dos episódios chuvosos durante a fase do dipolo negativo. (FERREIRA E MELLO, 2005; NOBREGA, SANTIAGO E SOARES, 2016).

O plúton Neoproterozoico que estrutura o Maciço de Água Branca é constituído por uma associação de biotita-hornoblenda, quartzo, álcalifeldspato fino a porfirítico, sienito e quartzo-monzonito. As depressões circundantes se estabelecem sobre o embasamento metamórfico da unidade Mesoproterozoica do Complexo Cabrobó (1.1 a 0.95 Giga anos - $\mathrm{Ga}$ ) e Paleoproterozoica do Complexo Belém do São Francisco (2.07 Ga) (BRITO NEVES et al., 1995; BRITO et al., 2009; MENDES et al., 2010 e SILVA et al., 2002).

No que concerne o contexto morfoestrutural, a área de estudo está inserida na porção sudoeste do Planalto da Borborema, fazendo parte do Domínio Pernambuco Alagoas (DELGADO et al., 2003). Corrêa et al., (2010), caracteriza esse domínio como sendo estruturado em rochas metamórficas com a presença de plútons brasilianos (850 a $500 \mathrm{Ma}$ ) dispostos em um alinhamento NNE-SSW, como o plúton Água Branca.

Em relação às unidades geomorfológicas (Figura 02), o maciço foi divido em modelado de denudação e modelado de agradação. Entre as unidades de denudação destaca-se a superfície de cimeira do maciço, com uma altitude média de $700 \mathrm{~m}$, quase destituída de coberturas eluviais in situ e com presença ubíqua de afloramentos rochosos. As encostas sem cobertura coluvial nos terços superiores são marcadas pela ocorrência de depósito de tálus na base. No entorno da área mais elevada do Maciço de Água Branca definem-se dois níveis de pedimento, um a $400 \mathrm{~m}$ e outro a $300 \mathrm{~m}$. Estes encontram-se com a escarpa do Maciço definindo um knick-point bem marcado com recobrimento por material detrítico.

Sobre os pedimentos ocorrem ainda relevos residuais (inselbergs) associados ao afloramento de apófises do plúton neoproterozoico principal. No que diz respeito aos modelados de agradação, ocorrem a unidade de encosta com cobertura coluvial, capeando vales incisos no interior do Maciço geralmente acima da cota de $400 \mathrm{~m}$, e os plainos aluviais com formas alongadas, adaptados à rede de fraturas regionais, onde predominam o entrincheiramento atual da drenagem sobre os depósitos fluviais inconsolidados. 
Figura 02 - Mapa de unidades geomorfológicas de Água Branca - AL.

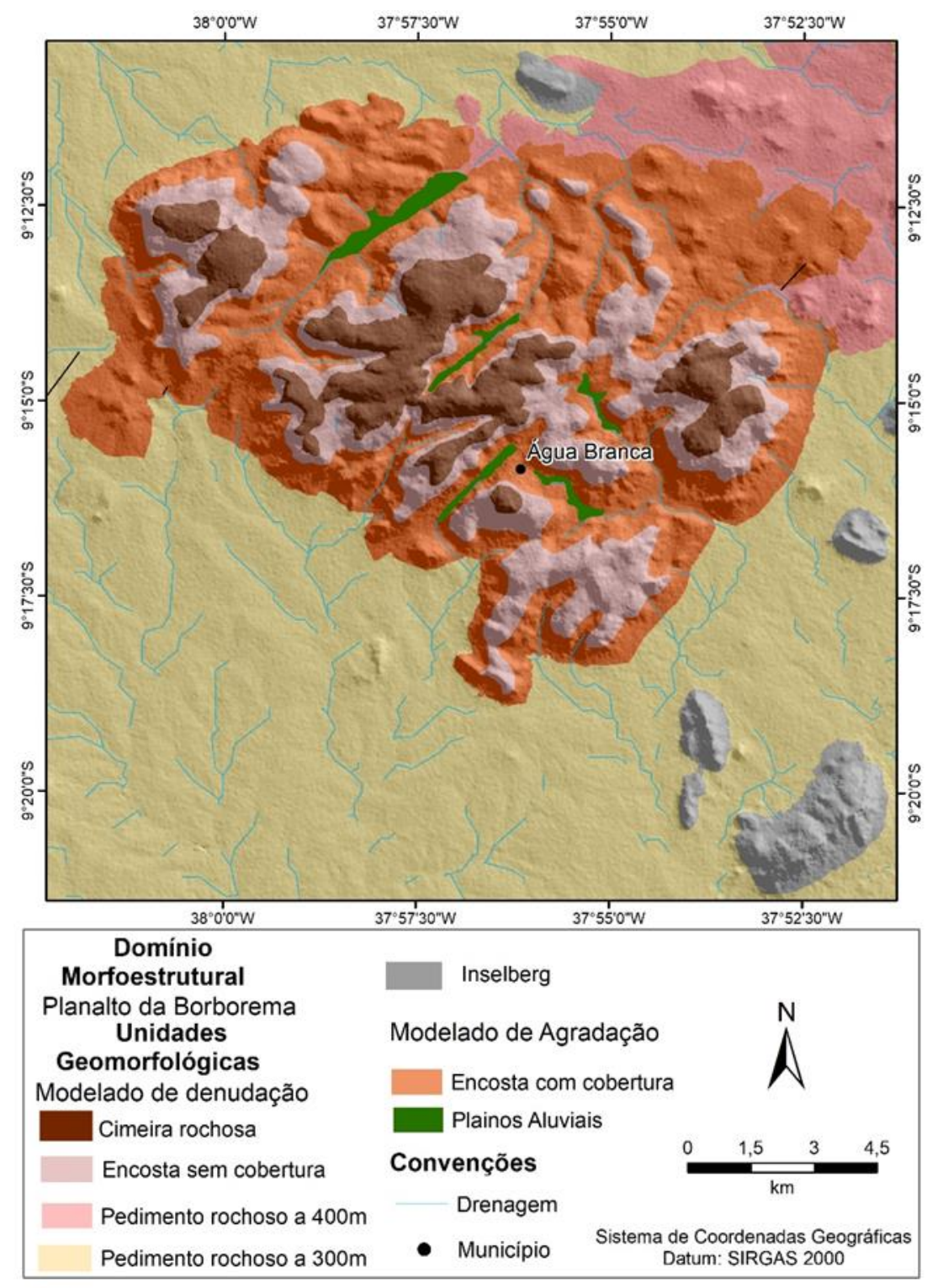

Fonte: Autores, 2020.

Quanto às cobertutras pedológicas, predominam na área interior do maciço os cambissolos háplicos, que ocorrem como solos pouco profundos, com alta suscetibilidade à erosão e normalmente associados à presença de depósitos de tálus. Verifica-se também a presença de uma mancha remanescente de argissolo vermelho sobre parte da cimeira do maciço. A área está inserida na bacia hidrográfica do rio Moxotó, tributário do rio São Francisco, com sistema de drenagem de padrão efêmero (EMBRAPA, 2006).

A vegetação potencial é a caatinga, com porte arbustivo-arbóreo e em alguns pontos mais elevados do maciço verifica-se a ocorrência de algumas espécies relacionadas às florestas semi-decíduas dos brejos de altitude. Não obstante, como atestado em campo, a maior parte da área do Maciço encontra-se sob formas 
tradicionais de uso da terra, como a policultura comercial e de subsistência e a pecuária, havendo essa última convertido boa parte da vegetação prístina em pastagem (EMBRAPA, 2006 e CPRM, 2005).

\section{Procedimentos metodológicos}

Em gabinete elaborou-se o mapa de unidades geomorfológicas, na escala de 1:100 000, a partir de observações dos modelados de relevo em campo, seguindo a metodologia proposta por Demek (1972), foram realizadas duas visitas à campo e estas serviram de guia para a identificação dos depósitos coluviais e realização das coletas de sedimentos.

No laboratório de Geomorfologia do Quaternário da Universidade Federal de Pernambuco foram efetuadas as análises granulométricas e morfoscópicas. No total processou-se 51 amostras, sendo 20 do perfil Preguiçoso e 31 referentes ao perfil Fórum. As amostras foram coletadas em intervalos contínuos de $10 \mathrm{~cm}$ nos perfis com a finalidade de se detectar mudanças texturais discretas que pudessem refletir alterações processuais macroscopicamente indiferenciadas.

A análise granulométrica foi conduzida conforme a metodologia proposta por Gale \& Hoare (1991), utilizando-se a escala de Wentworth para a classificação das frações. A fim de se obter mais informações sobre as características físicas dos sedimentos foram calculados os parâmetros estatísticos de grau de seleção dos sedimentos, assimetria e curtose, conforme Folk e Ward (1957), e elaborados os Diagramas de Shepard (1954) e Pejrup (1988). As análises foram executadas no software Sysgran 3.0.

A análise morfoscópica consistiu na descrição do grão quanto à sua forma, a partir do grau de arredondamento (muito angular, angular, sub-angular, subarredondado, arredondado e bem arredondado), esfericidade (prismoidal, subprismoidal, esférico, sub-discoidal e discoidal), textura (brilhosa, fosca ou polida), composição mineralógica e opacidade (transparente ou opaco). Os grãos foram examinados a partir da metodologia proposta por Tucker (1995), para tanto separouse 100 grãos de cada amostra na fração de 250mm, correspondente à areia média. Os sedimentos foram observados em uma lupa binocular e classificados de acordo com os parâmetros descritos anteriormente.

Foram coletadas 5 amostras para datação pelo método LOE, utilizando-se tubos de ferro galvanizado, com $30 \mathrm{~cm}$ de comprimento cada. Os tubos foram 
inseridos em níveis pré-definidos nos perfis e retirados sem obter contato com a luz solar. Processou-se as amostras na empresa Datação, Comércio \& Prestação de Serviços LTDA.

A técnica empregada foi a da luminescência opticamente estimulada (LOE), que consiste em lançar um feixe de luz polarizada a materiais previamente expostos à radiação ionizante ambiental, para que por meio da ação do agente excitante (feixe de luz) o material emita um sinal luminescente, proporcional ao tempo que esteve soterrado e recebendo o influxo da radiação do depósito. Para o cálculo da idade utilizou-se o protocolo SAR (single aliquot regenerative-dose), que busca determinar uma idade média para cada amostra, a partir da ponderação estatística das idades de várias sub-alíquotas. Nesse caso optou-se pelo uso de 15 subalíquotas por amostra datada.

\section{Resultados e discussões}

O primeiro ponto de coleta está localizado na cimeira do maciço a $728 \mathrm{~m}$ de altitude, e consiste em um depósito de colúvio que preenche uma paleo-concavidade que permitiu a retenção dos sedimentos, o perfil possui $2 \mathrm{~m}$ de espessura (Perfil Preguiçoso). O segundo ponto situa-se na baixa encosta de um vale retilíneo que secciona o Maciço em direção NE-SW, a aproximadamente $600 \mathrm{~m}$ de altitude. Tratase de um perfil em rampa com continuidade lateral, e espessura do material coluvial de 3,1m (Perfil Fórum). Ver figura 03. 
Figura 03 - Localização dos pontos de coleta inseridos no maciço de Água Branca - AL.

A - Perfil Preguiçoso, localizado na cimeira do maciço.
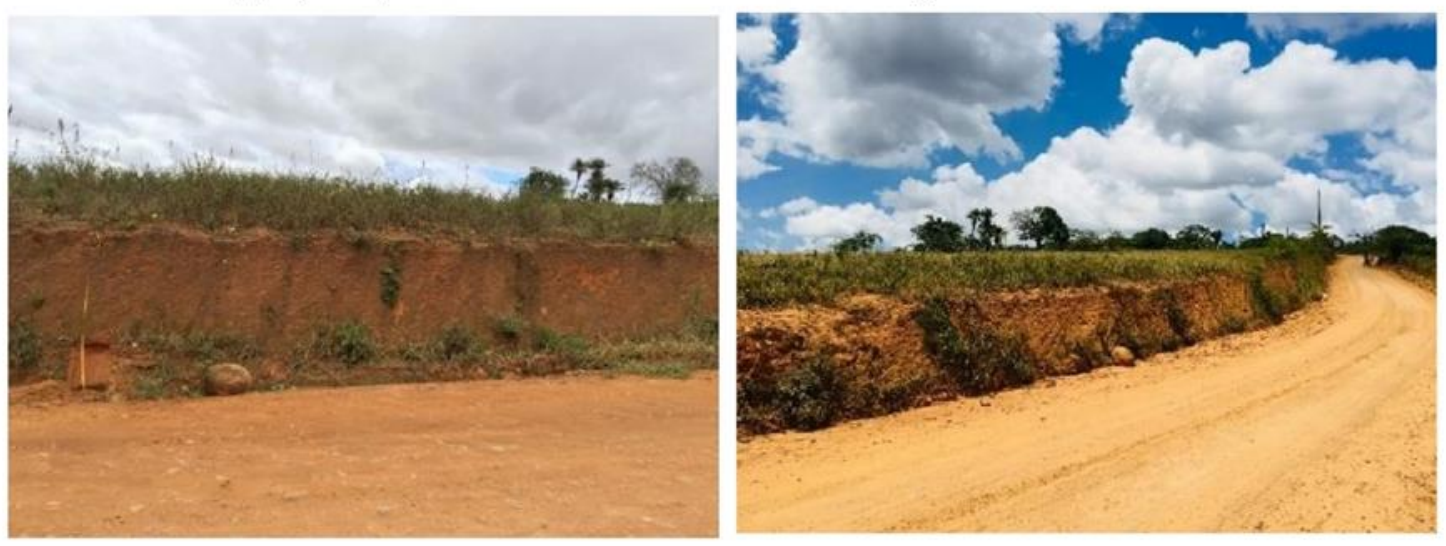

B - Perfil Fórum, localizado em setor de baixa encosta
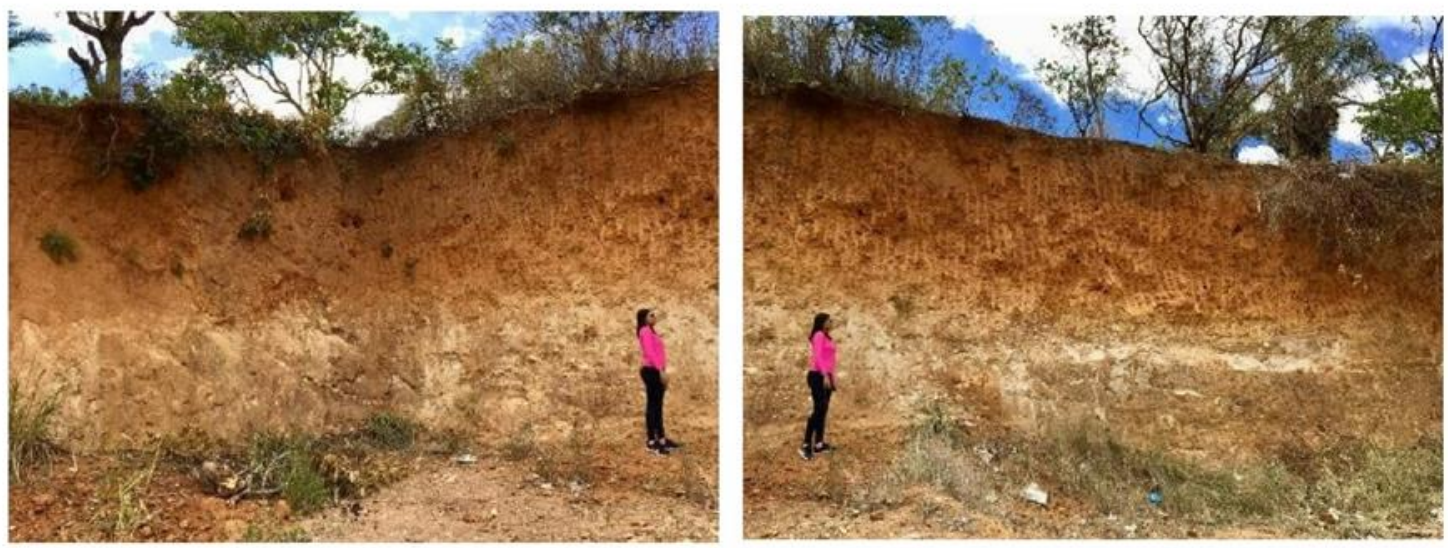

Fonte: Autores, 2020.

\section{Caracterização das seções}

No Perfil Preguiçoso foram coletadas 20 amostras de sedimento ao total (Figura 04). As letras A $(0,97 \mathrm{~cm})$ e $B(1,4 \mathrm{~m})$, representam as amostras coletadas para a datação por LOE, situadas acima e abaixo de uma cascalheira matriz suportada. O perfil é constituído por uma associação de cambissolo e argissolo e foi dividido em três litofáceis de acordo com as suas diferenciações morfoestratigráficas. Assim, a base com $40 \mathrm{~cm}$ de espessura é marcada pela presença de um sedimento arenoso com clastos na fração seixo e cor marrom (5 YR $5 / 8$ ) de acordo com a Carta de Munsell. A camada intermediária, possui $50 \mathrm{~cm}$ de espessura e constitui uma cascalheira matriz suportada, com clastos variando de grânulo a seixo ou, eventualmente, calhau, de cor laranja (5 YR 6/6). Já a camada do topo, a mais espessa $(1,1 \mathrm{~m})$, apresenta estrutura maciça sem descontinuidades visíveis, marcada por um sedimento arenoso com ocorrência eventual de cascalho na fração grânulo e seixo, e cor laranja (5 YR 6/8). 
Figura 04 - Perfil estratigráfico Preguiçoso.

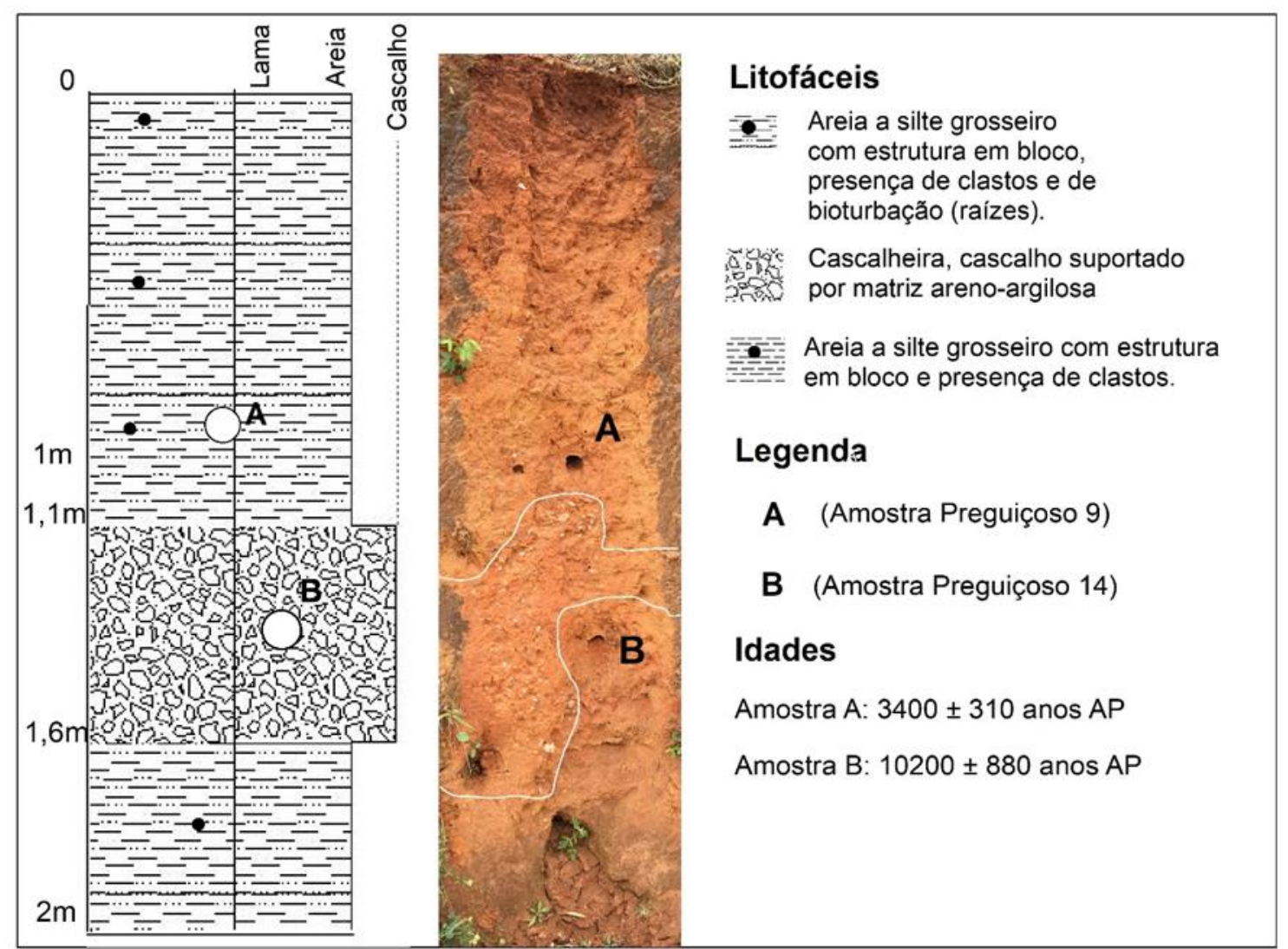

Fonte: Autores, 2020.

O Perfil Fórum foi a seção mais espessa analisada (Figura 05), trata-se de um material sem expressivas descontinuidades estratigráficas, com textura geral arenosa e aspecto maciço, sendo composto por rampas de argissolo com continuidade lateral. $O$ perfil também foi dividido em três setores para fins de coleta de amostras para datação. A base, com cerca de $40 \mathrm{~cm}$ de espessura e textura arenosa, apresenta cor laranja (7.5YR 6/6). A camada intermediária possui $1 \mathrm{~m}$ de espessura e cor marrom (7.5YR 5/8). Já a camada do topo com $1,7 \mathrm{~m}$, a mais espessa, também exibe cor marrom (7,5YR 4/6). Em todo o perfil observam-se clastos na fração grânulo e seixo e ocorre a predominância de bioturbação por raízes na camada mais próxima à superfície. Foram coletadas três amostras para a geocronologia, representadas pelas letras $A(1,1 \mathrm{~m}), \mathrm{B}(1,7 \mathrm{~m})$ e $\mathrm{C}(2,7 \mathrm{~m})$. 
Figura 05 - Perfil estratigráfico Fórum.

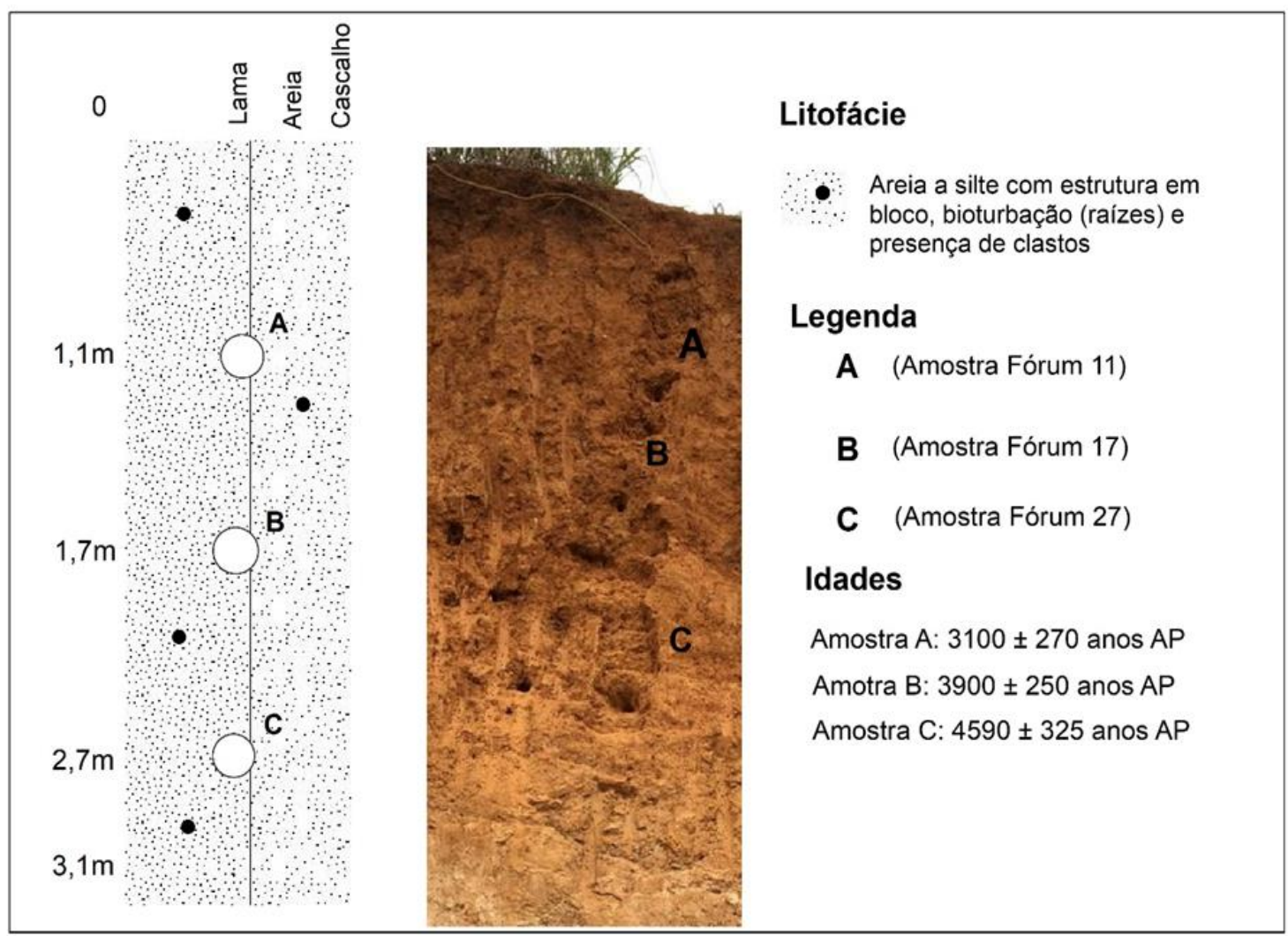

Fonte: Autores, 2020.

\section{Apresentação sedimentológica dos materiais}

No que concerne à granulometria, em todas as amostras do Perfil Preguiçoso predominaram as frações de areia grossa $(14,1 \%)$, areia média $(18,6 \%)$ e areia muito fina $(21,3 \%)$, (Figura 06$)$. Na análise morfoscópica em relação à esfericidade prevaleceram os grãos sub-prismoidais (56\%), sub-discoidais $(27 \%)$ e esféricos $(17 \%)$. Na classificação de arredondamento foram proeminentes os sedimentos angulares $(41 \%)$ e sub-angulares $(52 \%)$, indicando que os mesmos foram pouco trabalhados em seu transporte, e que o material possui área fonte próxima. A maior parte dos grãos são opacos e apresentam textura fosca com exceção dos grãos de quartzo que são transparentes e com textura brilhante. Na mineralogia têm-se grãos de quartzo, feldspato e algumas amostras com biotita e muscovita. 
Figura 06 - Granulometria do perfil Preguiçoso (Perfil organizado no sentido topo-base e profundidade em centímetros).

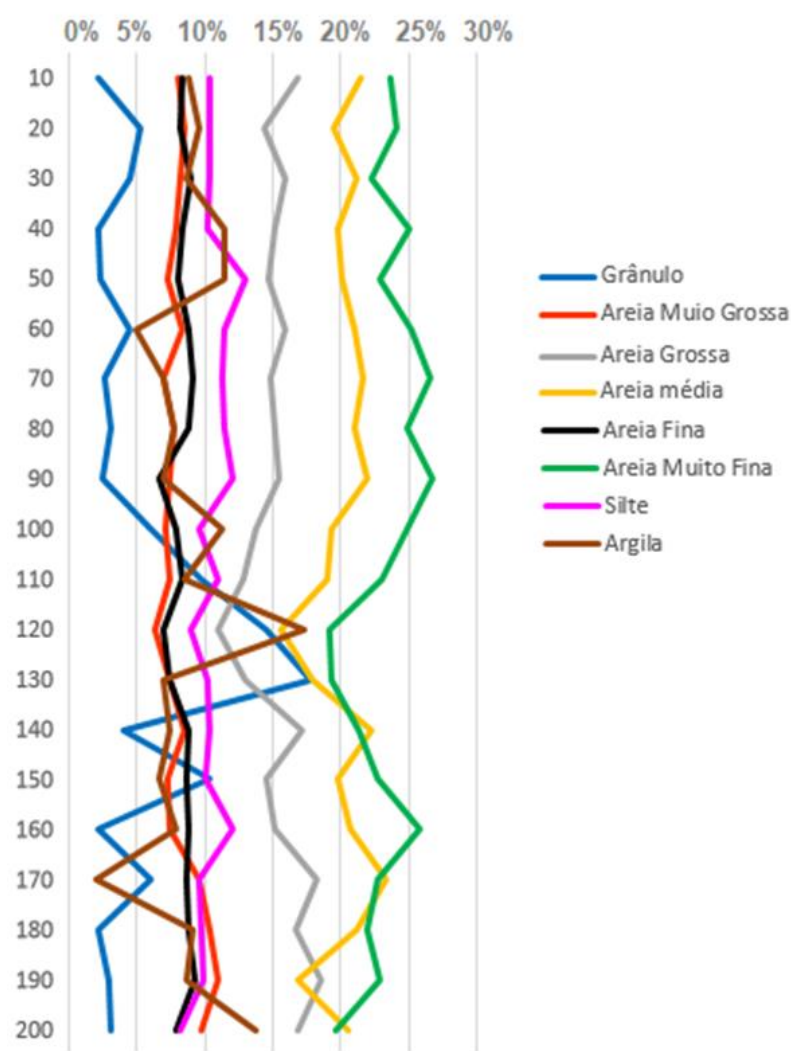

Fonte: Autores, 2020.

Elaborou-se também os diagramas de Shepard (1954) e Pejrup (1988), validando que todas as amostras do perfil possuem textura arenosa e são decorrentes de ambientes de hidrodinâmica alta a muito alta, o que sugere que um regime de elevada energia condicionou à deposição do material (Tabela 01). Utilizou-se também os parâmetros de Folk and Ward (1957) para a caracterização dos sedimentos, sendo eles o grau de seleção, a curtose e a assimetria. O grau de seleção para todas as amostras do perfil variou entre 1,57 e 2,1, classificando os grãos como pobremente selecionados $(0,1$ a 2,0$)$ e muito pobremente selecionados $(2,0$ a 4,0). Em relação à curtose os valores foram de 0,74 a 0,93 . A camada do topo, até $1,1 \mathrm{~m}$ de profundidade, foi classificada como mesocúrtica, com valor médio de 0,93 , com distribuição mais próxima à curva normal, exibindo menor variedade das frações granulométricas.

Já as camadas intermediárias $(1,1 \mathrm{~m}$ até $1,6 \mathrm{~m})$ e basal $(1,6 \mathrm{~m}$ à $2 \mathrm{~m})$ foram categorizadas como platicúrticas, com a curva de distribuição mais achatada, consequentemente com maior diversidade das frações granulométricas. No que diz respeito à assimetria, os valores são positivos caso haja concentração das partículas finas e negativos se a situação for o contrário. Nesse perfil os valores foram de 0,15 até 0,08 , englobando a categoria de aproximadamente simétrica a assimetria negativa. A camada da base e camada do topo foram classificadas como aproximadamente simétricas, com a maioria das amostras apresentando valores positivos, o que significa dizer que estão mais próximas a um enriquecimento em frações finas. A camada intermediária apresentou valores negativos em $90 \%$ das 
amostras e assimetria negativa, o que aponta para o enriquecimento em frações grossas, com a possível perda das frações mais finas.

Tabela 01 - Parâmetros sedimentológicos - Perfil Preguiçoso.

\begin{tabular}{c|ccccc} 
& $\begin{array}{c}\text { Grau de } \\
\text { seleção }\end{array}$ & Curtose & Assimetria & $\begin{array}{c}\text { Hidrodinâ- } \\
\text { mica }\end{array}$ & Textura \\
$\begin{array}{c}\text { Camada do } \\
\text { topo }\end{array}$ & $\begin{array}{c}\text { Probremente } \\
\text { selecionado }\end{array}$ & Mesocúrtica & $\begin{array}{c}\text { Aproximadamente } \\
\text { simétrica }\end{array}$ & Muito alta & Arenosa \\
$\begin{array}{c}\text { Camada } \\
\text { intermediária }\end{array}$ & $\begin{array}{c}\text { Pobremente } \\
\text { selecionado }\end{array}$ & Platicúrtica & $\begin{array}{c}\text { Assimetria } \\
\text { negativa }\end{array}$ & Alta & Arenosa \\
$\begin{array}{c}\text { Camada da } \\
\text { base }\end{array}$ & $\begin{array}{c}\text { Muito } \\
\text { pobremente } \\
\text { selecionado }\end{array}$ & Platicúrtica & $\begin{array}{c}\text { Aproximadamente } \\
\text { simétrica }\end{array}$ & Alta & Arenosa \\
& & & & & \\
\hline
\end{tabular}

Fonte: Autores, 2020

$\mathrm{Na}$ análise granulométrica do Perfil Fórum foram encontradas frações de grânulo a argila grossa, sendo maiores as proporções de areia grossa $(16,72 \%)$, areia média $(22,36 \%)$ e areia muito fina (20,38\%) (Figura 07). Os resultados da morfoscopia são semelhantes ao do Perfil Preguiçoso. Quanto à esfericidade, as maiores porcentagens foram de grãos sub-prismoidais (52\%), esféricos (18\%) e subdiscoidais (27\%), refletindo uma esfericidade média. No tocante ao arredondamento, destacaram-se os sedimentos angulares (43\%) e sub-angulares (48\%), mais uma vez, demonstrando que o material foi pouco trabalhado e que possui área fonte próxima. 
Figura 07 - Granulometria do perfil Fórum (Perfil organizado no sentido topo-base e profundidade em centímetros).

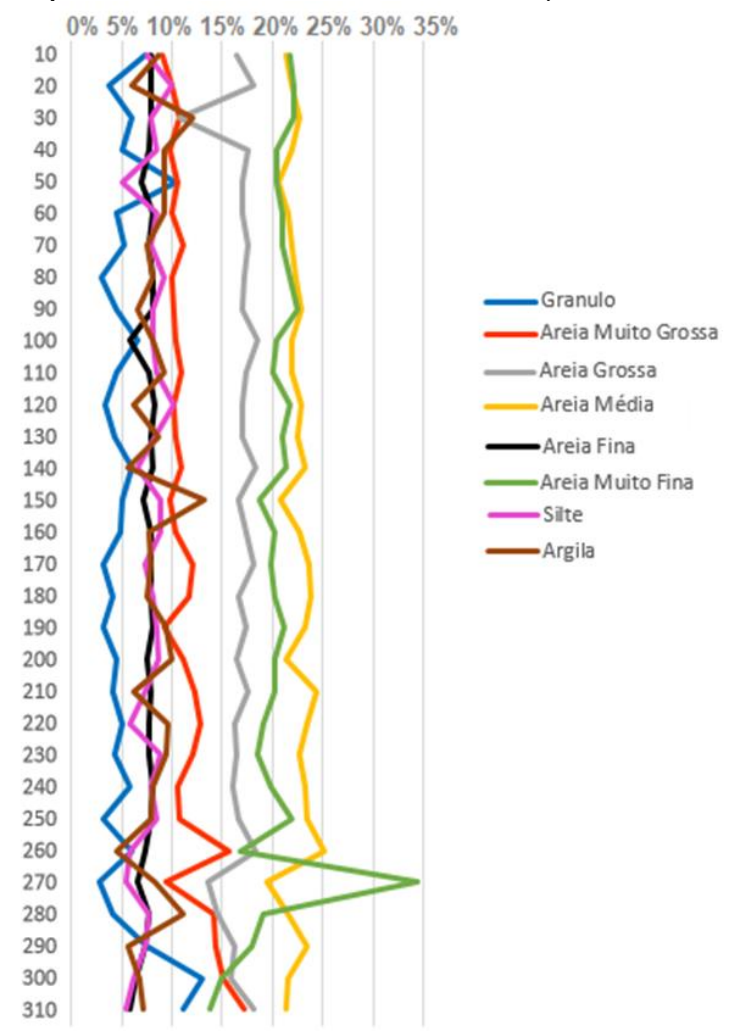

Fonte: Autores, 2020.

Os sedimentos são compostos por grãos de quartzo, feldspato em sua maioria e alguns grãos de magnetita e biotita. Sendo a maior parte deles opacos e foscos, com exceção de alguns grãos de quartzo transparentes e brilhantes. Os diagramas de Shepard (1954) e Pejrup (1988) mostram que todas as amostras do perfil possuem textura arenosa e hidrodinâmica alta (Tabela 02).

Os parâmetros de Folk and Ward (1957) revelaram que o grau de seleção para as amostras variou de 1,55 a 1,88, classificando os sedimentos como pobremente selecionados $(0,1$ a 2,0). Em relação à assimetria, os valores foram de - 0,08 até 0,09, as amostras do topo e do meio da seção foram categorizadas como aproximadamente simétricas, com uma aproximação do enriquecimento em partículas finas. As amostras da base apresentaram assimetria negativa, apontando o enriquecimento em partículas grosseiras, e perda relativa de finos. A curtose variou de $0,73 \mathrm{e}-1,01$, sendo as amostras dos níveis do topo e do meio da seção vertical consideradas platicúrticas, com a curva de distribuição das frações de sedimentos mais achatada do que a curva normal. Enquanto isso, algumas amostras da base foram categorizadas como platicúrticas e outras como mesocúrticas. 
Tabela 02 - Parâmetros sedimentológicos - Perfil Fórum.

$\begin{array}{llll}\text { Grau de } & \text { Curtose } & \text { Assimetria Hidrodinâmica Textura } \\ \text { seleção } & & & \end{array}$

\begin{tabular}{|c|c|c|c|c|c|}
\hline $\begin{array}{c}\text { Camada do } \\
\text { topo }\end{array}$ & $\begin{array}{l}\text { Probremente } \\
\text { selecionado }\end{array}$ & Platicúrtica & $\begin{array}{l}\text { Aproximadamente } \\
\text { simétrica }\end{array}$ & Alta & Arenosa \\
\hline $\begin{array}{c}\text { Camada } \\
\text { intermediária }\end{array}$ & $\begin{array}{l}\text { Pobremente } \\
\text { selecionado }\end{array}$ & Platicúrtica & $\begin{array}{c}\text { Aproximadamente } \\
\text { simétrica }\end{array}$ & Alta & Arenosa \\
\hline $\begin{array}{c}\text { Camada da } \\
\text { base }\end{array}$ & $\begin{array}{l}\text { Probremente } \\
\text { selecionado }\end{array}$ & $\begin{array}{l}\text { Platicúrtica/ } \\
\text { Mesocúrtica }\end{array}$ & $\begin{array}{c}\text { Assimetria } \\
\text { negativa }\end{array}$ & Alta & Arenosa \\
\hline
\end{tabular}

Fonte: Autores, 2020.

\section{Correlação cronoestratigráfica dos depósitos}

A fim de obter um panorama composto pelos dados geocronológicos deste trabalho, com os já existentes para a área, e tendo em mente o que as idades representam no contexto da dinâmica paleoambiental da região Nordeste, foi elaborado um mapa espacializando todas as datações já disponíveis para a área de estudo (Figura 08). 
Figura 08 - Mapa com idades de sedimentos no maciço de Água Branca- AL e em seu entorno

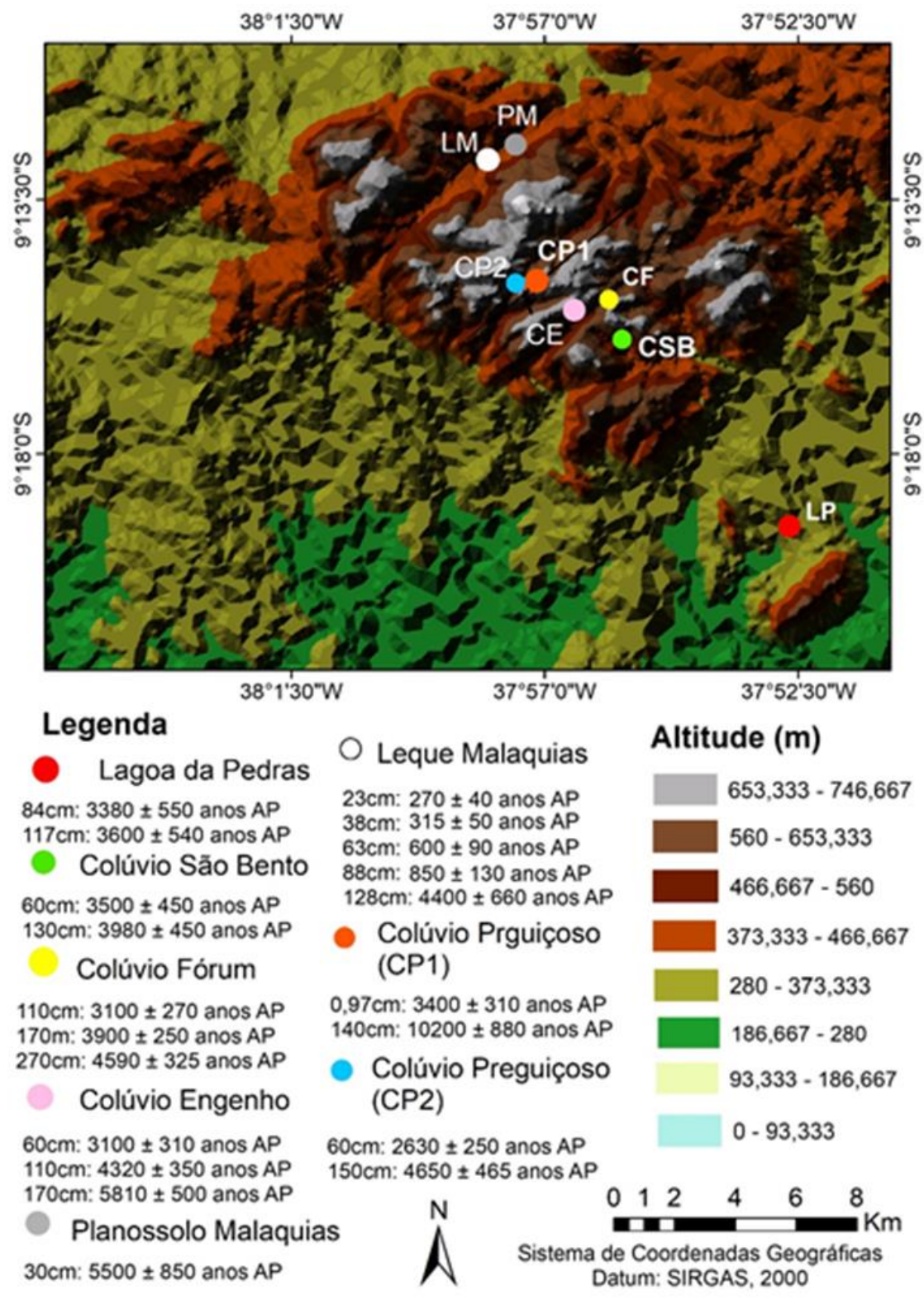

Fonte: Autores, 2020.

A maior parte das informações advém de depósitos coluviais, porém foram também consideradas idades provenientes de sedimentos de preenchimento de marmitas de dissolução (Lagoa das Pedras), leque aluvial (Leque Malaquias), e depósitos aluviais com planossolos (Planossolo Malaquias). As idades dos perfis Leque Malaquias (LM), Planossolo Malaquias (PM), Lagoa das Pedras (LP), Colúvio Engenho (CE), Colúvio São Bento (CSB) e Colúvio Preguiçoso 2 (CP2) resultam do trabalho de Melo (2019). Para diferenciar os dois perfis estudados no Sítio Preguiçoso, o perfil analisado neste trabalho foi chamado de Colúvio Preguiçoso 1 e o perfil de Melo (2019), foi denominado de Colúvio Preguiçoso 2. 
Com base na comparação das idades, pode-se afirmar que houve ao menos seis diferentes eventos de inputs de sedimentação sobre as unidades agradacionais da área. O primeiro momento ocorreu no Holoceno Inferior e corresponde a um único depósito desse período, $10200 \pm 880$ anos AP, localizado na base do Colúvio Preguiçoso 1. De acordo com o trabalho de Corrêa (2001), que analisou depósitos coluviais no Maciço da Serra da Baixa Verde - PE, este período foi marcado pela predominância de um clima úmido com a remobilização maciça das coberturas sedimentares, ocasionada possivelmente por chuvas torrenciais da ZCIT. Mutzenberg (2007), em sua pesquisa no Vale do Rio Carnaúba -RN, também sugere que durante este período ocorreu o retorno súbito da umidade causado por eventos chuvosos de alta magnitude, o que confere uma abrangência regional ao evento. Ademais, atesta-se a abrangência global de um período de maior umidade na transição Pleistoceno/Holoceno, e em particular nas áreas intertropicais (WANG et al., 2017 e NOVELO et al., 2017).

O segundo momento está relacionado com os depósitos de $5810 \pm 500$ anos AP, na base do Colúvio Engenho, a 560m de altitude, e $5500 \pm 850$ anos AP na base do Planossolo Malaquias. A distância entre esses dois perfis é de cerca de $6 \mathrm{~km}$ e ambos estão próximos às suas respectivas áreas fonte. O Planossolo Malaquias, por se tratar de um depósito aluvial, reflete a deposição de sedimentos oriundos de várias partes do relevo dentro da bacia, o que demonstra uma sincronicidade entre a deposição de encosta e a fluvial neste momento. O segundo momento tem relação com o terceiro, pois ambos estão associados a depósitos do Holoceno Médio. As idades do terceiro momento são de $4650 \pm 465$ anos AP na base do Colúvio Preguiçoso 2, $4590 \pm 325$ anos AP na base do Colúvio Fórum e $4400 \pm 660$ anos AP na base do Leque Malaquias. Durante essa fase do Holoceno em alguns locais do NE do Brasil ocorreu a manutenção da umidade, com picos de máxima umidificação e a remobilização dos sedimentos gerando depósitos ocasionados por fluxos de detritos e corridas de lama. Em locais como no Maciço da Serra da Baixa Verde PE, no Vale do Catimbau -PE e no Maciço do Pereiro - RN/CE, existem depósitos correspondentes ao máximo de umidade do Holoceno Médio que vão de aproximadamente 7500 anos AP a 4000 anos AP (CORRÊA, 2001; GALVÃO, 2012; GURGEL et al., 2013; LIRA 2014; MUTZENBERG, 2007 e SILVA, 2013).

A fase que se seguiu foi marcada pela diminuição gradativa da umidade e a instalação de um clima de semiaridez severa. Contudo, a dinâmica de deposição não cessou na área de estudo durante o Holoceno Superior e nesse intervalo de 
tempo ocorreram mais três prováveis episódios, o mais antigo de $3980 \pm 450$ anos AP na base do Colúvio São Bento e $3900 \pm 250$ anos AP na camada intermediária do Colúvio Fórum. Esses depósitos estão próximos entre si, a uma distância de $1,4 \mathrm{~km}$ e possuem área fonte comum. Outro evento, de $3500 \pm 450$ anos AP ocorre no topo do Colúvio São Bento e $3400 \pm 310$ anos AP no topo do Colúvio Preguiçoso 1. Por último, o episódio mais recente resultou em duas idades de 3100 anos AP, uma localizada no topo do Colúvio Fórum (3100 \pm 270 anos AP) e outra no topo do Colúvio Engenho (3100 \pm 310 anos AP), em ambos os casos as idades apresentamse bem próximas entre si. Acredita-se que os eventos responsáveis por essas deposições estão relacionados às chuvas torrenciais geograficamente localizadas, uma vez que esse período é reconhecidamente marcado por um clima semiárido severo em vários setores da região Nordeste (CORRÊA, 2001; GURGEL et al., 2013; LIRA, 2014 e SILVA, 2013).

Além disso, no Colúvio Fórum e no topo do Colúvio Preguiçoso 1, verificou-se a predominância de sedimentos mais finos, ausência de fluxos de detrito, sugerindo deposição dominada por fluxos de lama. Neste caso, a falta de expressivas descontinuidades litológicas, como a ocorrência de cascalheiras matriz suportadas, atestam o predomínio de processos de magnitude semelhante, mas incapazes de atingir em maior profundidade o perfil de intemperismo a ponto de remobilizar os fragmentos rochosos presentes na frente de alteração.

Condição semelhante deu-se no único depósito do Holoceno Superior, encontrado na pesquisa de Corrêa (2001), no Maciço da Serra da Baixa Verde- PE. Onde o colúvio com idade de 4700 anos AP, apresenta caráter maciço, textura arenosa e ausência de fenoclastos. O autor acredita que o depósito tenha sido formado pela acentuação da erosão laminar no local, após a remoção dos grossos da encosta em eventos anteriores.

Considerações finais

Os resultados obtidos apontam que existem registros de depósitos sedimentares, ainda armazenados nos compartimentos de estocagem da área de estudo, abrangendo três fases climáticas do Holoceno de expressão sobre a cronologia dos modelados de agradação regional. A acumulação coluvial mais antiga encontrada remonta ao Holoceno Inferior, com idade de $10200 \pm 880$ anos AP, próximo à superfície de cimeira do maciço, a 728m de altitude. Esta posição na paisagem dos sedimentos do Holoceno Inferior corrobora a interpretação de uma 
sedimentação em cascata para a área, onde os sedimentos mais antigos estão sobre as maiores altitudes.

A dinâmica de sedimentação não cessou no maciço de Água Branca durante o Holoceno Médio, no total existem quatro depósitos dessa época para a área, embora apenas um resulte diretamente desta pesquisa. A diminuição gradual da umidade característica do avanço do Holoceno Médio, associada por alguns autores à retomada dos eventos cíclicos do ENOS e ao recrudescimento da célula de Hadley, pode ter se refletido na menor capacidade em gerar fluxos gravitacionais. Assim, os eventos responsáveis pela sedimentação neste intervalo, estão ligados às chuvas torrenciais, provocadas por picos de umidificação do clima durante e imediatamente após o Ótimo Climático do Holoceno (CORRÊA et al., 2019; CORRÊA, 2001; GALVÃO, 2012; GURGEL et al., 2013; LIRA, 2014 e SILVA, 2013).

O hiato de deposição identificado na área entre 10200 anos AP e 5800 anos AP, pode estar relacionado a uma fase de estabilização geomórfica da paisagem, pela expansão da cobertura vegetal, como ocorre nas pesquisas de Silva (2013) e Mutzenberg (2007).

Ademais, sobram registros de deposição do Holoceno Superior para a área. Presume-se que apesar desse período ter sido marcado pela predominância de um clima semiárido mais severo no interior do Nordeste, devido à estabilização da circulação contemporânea e influencia cíclica dos eventos ENOS e do Dipolo do Atlântico sobre a precipitação (Gurgel et al., 2013), ocorreram localmente eventos de torrencialidade aumentada. Esses episódios contemporaneamente são desencadeados por elementos da circulação atmosférica capazes de gerar precipitações torrenciais em nível local (Corrêa et al., 2019), como os Complexos Convectivos de Mesoescala (CCMs), Linhas de Instabilidade e ondulações ao sul da ZCIT, que podem ter sua atuação intensificada pela presença de controles tais como o Dípolo do Atlântico, durante sua fase negativa, além da presença dos maciços residuais cuja orografia redinamiza o efeito desses sistemas. Assim, crê-se que esses componentes da circulação regional funcionaram como desencadeadores climáticos para a geração de colúvios.

Esses podem ter atuado de forma mais eficaz sobre a remoção de solos expostos, ou sob cobertura vegetal esparsa, após episódios prolongados de seca, fora do registro histórico. Acredita-se também que o tipo de uso da terra na área, a partir da ocupação agrícola com a chegada dos primeiros grupos ceramistas há 
cerca de 3000 anos AP, tenha agido em consórcio para a geração desses depósitos mais recentes (CORRÊA, 2001 e MARTIN, 2005).

De uma maneira geral os dois perfis analisados possuem características granulométricas e morfoscópicas semelhantes. Os depósitos foram formados majoritariamente por uma sucessão de fluxos de lama com a presença de clastos soltos, indicando um regime pulsátil de deposição. Encontrou-se apenas uma camada formada por fluxo de detrito, no Perfil Preguiçoso, representando um evento de maior energia, capaz de transportar sedimentos mais grossos, sendo reflexo de uma condição momentânea de torrencialidade aumentada.

\section{REFERÊNCIAS}

BEZERRA, F. H. R.; BRITO NEVES, B. B.; CORRÊA, A. C. B.; BARRETO, A. M. F.; SUGUIO, K. Late Pleistocene tectonical-geomorphological development within a passive margin - The Cariata trough northeastern Brazil. Geomorphology, Amsterdam, v. 97, i. 3-4, p. 555-582, 2008.

BRITO, M. F. L. de.; FILHO, A. F. da S.; GUIMARÃES I. de P. Caracterização geoquímica e isotópica do batólito Serra do Catu e sua evolução da interface dos domínios Sergipano e Pernambuco-Alagoas, Província Borborema. Revista Brasileira de Geociências, São Paulo, v. 39, n.2, p. 324-337, jun. 2009.

BRITO NEVES, B. B.; VAN SCHMUS, W. R.; SANTOS, E .J.; CAMPOS NETO, M. C.; KOZUCH, M. O evento Carirís Velhos na Província Borborema: integração de dados, implicações e perspectivas. Revista Brasileira de Geociências, São Paulo, v. 25, n.4, p. 279-296, dez. 1995.

CORRÊA, A. C. B.; TAVARES, B. A. C.; LIRA, D. R.; MUTZENBERG, D. S.; CAVALCANTI, L. C. S. (2019) The Semi-arid Domain of the Northeast of Brazil. In: SALGADO, A.; SANTOS L.; PAISANI J. (ed.). The Physical Geography of Brazil. Geography of the Physical Environment. Cham: Springer, 2019. p.119-150.

CORRÊA, A. C. B.; TAVRES, B. A. C.; MONTEIRO, K. A.; CAVALCANTI, L. C. S.; LIRA, D. R. Megageomorfologia e Morfoestrutura do Planalto da Borborema. Revista do Instituto Geológico, São Paulo, v. 31, n.1/2, p. 35-52, 2010.

CORRÊA, A. C. B. Dinâmica geomorfológica dos compartimentos elevados do Planalto da Borborema, Nordeste do Brasil. 2001. Tese (Doutorado em Geografia) - Universidade Estadual Paulista, Rio Claro, 2001.

CPRM, Serviço Geológico do Brasil. Projeto cadastro de fontes de abastecimento por água subterrânea. Diagnóstico do município de Água Branca, estado de Alagoas. Recife: CPRM/PRODEEM, 2005, 13 p. + anexos.

DELGADO, J. de M. et. al. Geotectônica do escudo Atlântico. In: BIZZI, L. A.; SCHOBBENHAUS, C.; VIDOTTI, R. M.; GONÇALVES, J. H. (org.). Geologia, tectônica e recursos minerais do Brasil: Texto, mapa e GIS. Brasília: CPRM, 2003. p.227-335. DEMEK, J. (ed.). Manual of detailed geomorphological mapping. Praga: Comm. Goomorph. Surv. Mapping. IGU, 1972. 
EMBRAPA. Solos do Município de Água Branca, Estado de Alagoas, 2006. Disponível em:https://ainfo.cnptia.embrapa.br/digital/bitstream/item/115501/1/ComTec-40-AguaBranca.pdf. Acesso em 17 de julho. 2020.

FERREIRA, A. G; MELLO, N. G. da S. Principais sistemas atmosféricos atuantes sobre a região Nordeste do Brasil e a influência dos Oceanos Pacífico e Atlântico no clima da região. Revista Brasileira de Meteorologia, São José dos Campos, v.1, n. 1, p.15-28, dez. 2005.

FOLK, R. L. \& WARD, W. Brazos river bar: a study in the significance of grain size parameters. Journal of Sedimentary Research, USA, v. 27, n. 1, p. 3-26, Mar. 1957.

GALE, S. J. \& HOARE, P. G. Quaternary sediments: petrographic methods for the study of ulithified rocks. Londres: Bethaven Press, 1991.

GALVÃO, D. C. Reconstrução paleoambiental a partir dos colúvios do entorno da lagoa do Puiu, município de lbimirim-Pernambuco. 2012. Dissertação (Mestrado em Geografia) - Universidade Federal de Pernambuco, Recife, 2012.

GURGEL, S. P. P.; BEZERRA, F. H. R.; CORRÊA, A. C. DE B.; MARQUES, F. O.; MAIA, R. $P$. Cenozoic uplift and erosion of structural landforms in NE Brazil. Geomorphology, Amsterdam, v. 186, p.68-84, Mar. 2013.

LIRA, D. R. Evolução geomorfológica e paleoambiental das bacias do riacho do pontal e GI-8 no sub-médio São Francisco/PE. 2014. Tese (Doutorado em Geografia) Universidade Federal de Pernambuco, Recife, 2014.

MABESOONE, J. M. Sedimentologia. Recife: Editora Universitária, 1983.

MARTIN, G. Pré-História do Nordeste do Brasil. 4. ed. Recife: UFPE, 2005.

MELO, R. F. T. Evolução geomorfológica em bases paleoclimáticas do maciço estrutural de Água Branca - AL. 2019. Tese (Doutorado em Geografia) - Universidade Federal de Pernambuco, Recife, 2019.

MENDES, V. A.; LIMA, M. A. B.; MORAIS, D. M. F. de. Geologia e Recursos Minerais do Estado de Alagoas, SC.24-X-D. Escala 1:250.000. Estado de Alagoas. Recife: CPRM Serviço Geológico do Brasil, 2010.

MUTZENBERG, D. S.; CORREA, A. C. B.; TAVARES, B. A. C.; CISNEIROS, D. (2015) Serra Da Capivara National Park: Ruinform Landscapes on The Parnaiba Cuesta. In: VIEIRA. B.; Salgado A.; SANTOS L. (ed.). Landscapes and Landforms of Brazil. World Geomorphological Landscapes. Dordrech: Springer, 2015. p.253-263.

MUTZENBERG, D. S. Gênese e ocupação pré-histórica do Sítio Arqueológico Pedrado Alexandre: uma abordagem a partir da caracterização paleoambiental do Vale do Rio Carnaúba - RN. 2007. Dissertação (Mestrado em Arqueologia) - Universidade Federal de Pernambuco, Recife, 2007.

NOBREGA, R. S.; SANTIAGO, G. A. C. F.; SOARES, D. B. Tendências do controle climático oceânico, sob a variabilidade temporal da precipitação no Nordeste do Brasil. Revista Brasileira de Climatologia, Curitiba, v. 18, p.276-292, jan/jun. 2016. ISSN: 1980-055x. NOVELLO, V. F.; CRUZ, F. W.; VUILLE, M. et. al. A high-resolution history of the South American Monsoon from Last Glacial Maximum to the Holocene. Scientific Reports 7, London, n.44267, p.1-8, Mar. 2017.

PEJRUP, M. The triangular diagram used for classification of estuarine sediments: a new approach. In: DE BOER, P. L.; VAN GELDER, A.; NIO, S. D. (ed.). Tide-Influenced Sedimentary Environments and Facies. Ridel: Dordrecht, 1988, p.289-300.

SALGADO-LABOURIAU, M. L. História ecológica da terra. 2. ed. São Paulo: Edgard Blucher, 1994.

SELBY, M. J. Earth's Changing Surface. London: Clarendon, 1993. 
SEPLAG, Secretaria de Estado do Planejamento, Gestão e Patrimônio. Dados de

Precipitação Mensal do município de Água Branca. Disponível em:

http://dados.al.gov.br/it/dataset/dados-de-precipitacaomensal. Acesso em: 20 de junho. 2018.

SHEPARD, F. P. Nomenclature based on sand - silt - clay ratios. Journal of Sedimentary Petrology, Boulder, v. 24, p.151-158, 1954.

SILVA, D. G. da. Reconstrução da dinâmica geomorfológica do semiárido brasileiro no Quaternário superior a partir de uma abordagem multiproxy. 2013. Tese (Doutorado em Geografia) - Universidade Federal de Pernambuco, Recife, 2013.

SILVA, L. C.; ARMSTRONG, R.; PIMENTEL, M. M.; SCANDOLARA, J.; RAMGRAB, G.; WILDNER, W.; ANGELIM, L. A. A.; VASCONCELOS, A. M.; RIZZOTO, G.; QUADROS, M. L. E. S.; SANDER, A.; Rosa A. L. Z. Reavaliação da evolução geológica em terrenos précambrianos brasileiros com base em novos dados U-Pb SHRIMP, Parte III: Províncias Borborema, Mantiqueira meridional e Rio Negro-Juruena. Revista Brasileira de Geociências, São Paulo, v. 32, n.4, p.529-544, dez. 2002.

SUGUIO, K. Geologia do Quaternário e mudanças ambientais. 2. ed. São Paulo: Oficina de Textos, 2010.

TUCKER, M. Techniques in sedimentology. London: Blackwell, 1995.

WANG, X.; EDWARDS, R. L.; AULER, A. S. et. al. Hydroclimate changes across the Amazon lowlands over the past 45,000 years. Nature 541, London, v. 541, p.204-207, jan. 2017.

\section{NOTAS DE AUTOR}

\section{CONTRIBUIÇÃO DE AUTORIA}

Maria Luísa Gomes da Silva - Coleta de dados, análise de dados, concepção e elaboração do manuscrito. Flávia Jorge de Lima - Coleta de dados. Participação ativa da discussão dos resultados. Revisão e aprovação da versão final do trabalho.

Antônio Carlos de Barros Côrrea - Participação ativa da discussão dos resultados. Revisão e aprovação da versão final do trabalho.

\section{FINANCIAMENTO}

Os autores gostariam de agradecer à Fundação de Amparo à Pesquisa do Estado de Alagoas (FAPEAL), pelo financiamento para a realização das datações. No projeto intitulado: Processos superficiais atuais e quaternários da paisagem geomorfológica: uma análise a partir dos depósitos alúvio-coluviais do maciço de Água Branca e seu entorno, semiárido de Alagoas. UNIVERSAL FAPEAL № 04/2016. PROCESSO № 60030 1069/2016.

\section{CONSENTIMENTO DE USO DE IMAGEM}

Não se aplica.

\section{APROVAÇÃO DE COMITÊ DE ÉTICA EM PESQUISA}

Não se aplica.

CONFLITO DE INTERESSES

Não se aplica.

\section{LICENÇA DE USO}

Este artigo está licenciado sob a Licença Creative Commons CC-BY. Com essa licença você pode compartilhar, adaptar, criar para qualquer fim, desde que atribua a autoria da obra.

\section{HISTÓRICO}

Recebido em: 19-09-2019

Aprovado em: 18-12-2020 